aged in 2 to 6 years and in 6 to 12 years. Fracture was the leading cause of adolescents aged in 12 to 18 years. Congenital anomaly decrease in infant stage but pneumonia still threatened children aged in 2 to 6 years and 6 to 12 years.

Conclusions The characteristics of major health problems were different among age variables in children. All health promotion programs and policies should effectively provide the respective services and measure the outcome efficiently.

\section{P0-0959 UNDERSTANDING PARENT-PAEDIATRICIAN PARTNERSHIPS: THE FACTOR STRUCTURE OF THE PARENT PAEDIATRICIAN PARTNERSHIP SCALE (PPPS)}

J Pascoe, M Dressing, G Eberhart, R Rapp. Pediatrics, Wright State University, Dayton, USA

\subsection{6/archdischild-2014-307384.1578}

Background and aims This study was conducted as the second phase in the development of the Parent Paediatrician Partnership Scale (PPPS). Our objective was to identify the latent factor structure among thirty-two items relating to partnership between parents and paediatricians and identify the parent/child characteristics that were associated with each factor.

Methods Thirty-two items relating to partnership were administered to three-hundred and twenty five parents. The sample population was White (70.4\%), had a family income of over $\$ 35,000$ (50.6\%), had at least some college education $(70.4 \%)$, and the index child was male (61.3\%). About one-half of the parents were interviewed in a community practice ( $\mathrm{n}=157$; $48.3 \%)$ and the remainder in sub-specialty clinics located in a children's hospital ( $\mathrm{n}=168 ; 51.7 \%)$. The 32 items were entered in a factor analysis that produced five clearly defined factors.

Results The factors included Parental Involvement (PI, 4 items), Paediatrician Sensitivity (PS, 7 items), Communication (Co, 4 items), Access (Ac, 2 items) and a broad Comprehensive factor (BC, 13 items). Parent/child characteristics and their use of the practice or clinic were examined for their bivariate relationships with each factor. Although several characteristics were associated with factors, setting (community practice or sub-specialty clinic) was the most robust characteristic, associated with four of five factors.

Conclusion Partnership between parents and their children's paediatrician involves several elements, including a paediatrician's willingness to provide a parent with the opportunity to be involved and a paediatrician's ability to have a non-judgmental attitude, treat parent and child with dignity, and have sensitivity to a parent's moods.

\section{P0-0960 HOW ARE CLINICAL PRACTICE GUIDELINES PERCEIVED BY PHYSICIANS IN A MIDDLE EASTERN COUNTRY?}

M Hendaus, A Al-hammadi, E Razik, L Al-naimi. Pediatrics, Hamad General Hospital, Doha, Qatar

\subsection{6/archdischild-2014-307384.1579}

Background Clinical practice guidelines (CPGs) are proposals for clinicians about the care of patients and are usually described as 'systematically developed statements to assist practitioners and patients' decisions about appropriate health care for specific circumstances'.

Aims The aim of this study was to investigate the paediatricians' perceptions towards clinical practice guidelines at Hamad Medical Corporation (HMC) in Qatar.
Method A cross-sectional study was conducted at HMC between May and August 2013 using a validated self-administered questionnaire that was distributed to 240 paediatricians.

Results A total of 169 questionnaires were completed (response rate $70.4 \%$ ). Our main finding was that paediatricians at all levels are familiar with CPGs and use them. In addition, our doctors believe that CPGs lead to good quality of care, are practical, provide standardised patient care, will keep them up to date, decrease the rate of litigation, are evidence based, do not restrict continuity of self-education, do not alter physician esteem, lead to improvement of outcome, and are practical. However, the perceived barriers are that they affect clinical judgment, don't match with paediatricians' practice style, and that they don't reduce healthcare cost.

Conclusions Paediatricians at HMC have positive practice and perception towards CPGs. The results of our study suggest that CPGs are likely to be implemented if more counselling and education are provided to paediatricians regarding the usefulness of evidence based guidelines. In addition a program should be initialized to remove barriers, while simultaneously addressing physicians' concerns.

\section{PO-0961 PATIENT FEEDBACK MATTERS-FACILITATING IN A PAEDIATRIC AMBULATORY UNIT SETTING}

AM McClean, JS Woodside, M Anandarajan, K Dunlop, K Orr, R Kelly. Paediatrics, Ulster Hospital, Belfast, UK

\subsection{6/archdischild-2014-307384.1580}

Background and aims Service review work in 2013 revealed that Ulster Hospital paediatric ambulatory unit was receiving low numbers of written feedback from families compared to paediatric and neonatal wards. Aims were to improve patient feedback in paediatric ambulatory unit and to utilise feedback to aid delivery of safe, high quality care.

Methods An anonymised feedback and comment card was given to all patients attending the unit over a 4 week period in December 2013. This card allowed parents and patients to rate 5 aspects of care (staff attitude, communication, response to / disruption to child's needs and respect) from 1 (least satisfied) to 5 (most satisfied). Organisational strategies were put in place following the initial audit and cycle completed by re-auditing for 4 weeks in February 2014.

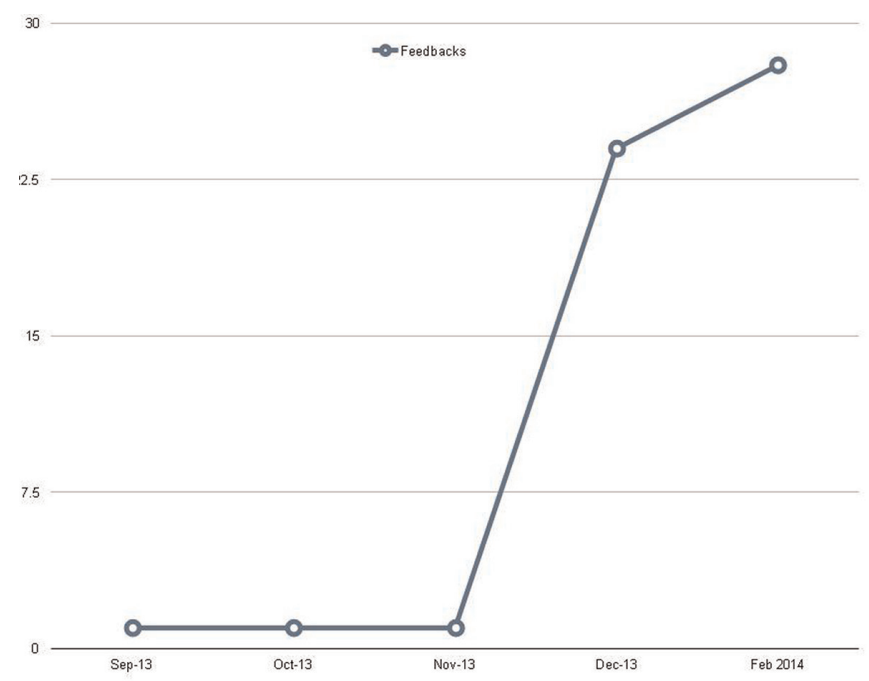

Abstract P0-0961 Figure 1 